\title{
The geography of HFE mutations: molecular diagnosis of haemochromatosis and the globalization of genetic testing
}

\author{
European Journal of Human Genetics (2004) 12, 877-878. doi:10.1038/sj.ejhg.5201265
}

Published online 1 September 2004

We read with great interest the comprehensive review by Godard et al in Eur J Human Genet ${ }^{1}$ on population-screening programmes. The review highlights hereditary haemochromatosis $(\mathrm{HH})$ as a potential disease for genetic screening (p S58), as well as the difficult matter of genetic testing commercialization (S67-S68). Hereby, we would like to draw the reader's attention to another important issue, to a certain extent related to commercialization, namely how the patent for genetic testing influences genetic diagnosis and may indeed have important implications for population-based studies. We would like to illustrate this point by reporting our experience with the $\mathrm{HH}$ molecular diagnostic testing in Singapore. $\mathrm{HH}$ is an inherited iron absorption abnormality due to mutations in the HFE gene. ${ }^{2,3}$ In particular, homozygous mutations $\mathrm{C} 282 \mathrm{Y}$ and $\mathrm{H} 63 \mathrm{D}$ are responsible for about $62-100 \%$ of $\mathrm{HH}$ worldwide. ${ }^{4}$ The low frequency of these mutations in Asian populations is presumed to be the cause of the very low incidence of $\mathrm{HH}$ in that part of the world. ${ }^{4}$ Hence, it could be presumed that $\mathrm{HH}$ genetic analysis in a South-east Asian molecular diagnostic laboratory would be a low-volume test with a minuscule number of positive results.

Our laboratory validated the $\mathrm{HH}$ molecular test for the analysis of the HFE C282Y and H63D mutations according to published protocols, ${ }^{5}$ and in the context of full accreditation by the College of American Pathologists. In 4 years, a total of 56 tests have been ordered by local clinicians. Of these, 10 (18\%) were homozygous for the C282Y mutation, while none exhibited H63D homozygosity. Heterozygosities for C282Y or H63D were 6 (11\%) and 14 (25\%), respectively, while compound C282Y/H63D heterozygosity was noted in three cases (5\%). This number of detected mutations (including a $18 \%$ of $\mathrm{C} 282 \mathrm{Y}$ homozygosity) is quite remarkable, particularly when in some European countries the frequency of $H F E \mathrm{C} 282 \mathrm{Y}$ mutations in clinically proven $\mathrm{HH}$ patients can be as low as 33 or $67 \%$. ${ }^{4}$ And, yet, the frequency of $\mathrm{HH}$ in Singaporeans is remarkably low, as is heterozygosity for these mutations in the general population ( $\sim 0.5 \%$, Koay, unpublished data). How do we explain this apparent contradiction?
Singapore is a highly developed society with a significant number of Caucasian expatriates. This is a highly educated, health-conscious group. In some instances, it was the patient who learnt that our laboratory was performing the test and called us directly, with us putting them in contact with the appropriate clinician who would evaluate the clinical implications of the test, request the test itself and offer or arrange genetic counselling prior to and after the test result.

Thus, it is not surprising that 33 (59\%) of the patients tested were Caucasian. This is the group in which all the homozygosity and most of the heterozygosity (except for six H63D heterozygous patients) were detected. In other words, 10 out of 33 (30\%) of our Caucasian patients were homozygous for C282Y.

We would like to suggest that the phenomenon of a highly educated, migrating population seeking genetic testing may be an important factor in understanding the distribution of diseases worldwide, and may influence the choice of test availability and test validation. In general, this tendency may quickly modify the prevalence of certain genetic diseases in countries where their prevalence was very low if the migrants are from a country of high prevalence. Furthermore, it could be that the racial profile of patient mix presenting to us may be modulated by the globalization of genetic testing. In the February 2002 issue of Nature, Merz et $a l^{6}$ illustrated how the patenting and licensing of genes is becoming an integral part of contemporary medical care, and US genetic laboratories are refraining to offer the HFE mutation test because of the patent. This may be the case in Europe soon $^{6}$ while in other places, due to the relative paucity of tests for a given disease, patents are not so vigorously enforced. We feel that a significant percentage of the Caucasian patients we diagnose may be taking advantage of a patent-free environment (albeit for the $\mathrm{HH}$ testing, and just for the moment). Interestingly, these patients will have a 'genetic diagnosis' that does not necessarily feature in their home healthcare records. As a whole, this represents a clear example of the economy of genetics and globalization of health care economics, a tendency that may indeed modulate the routine diagnostic practice of many molecular 
diagnosticians, and eventually dictate genetic screening programmes worldwide.

M Salto-Tellez ${ }^{1,2}$ and E Siew-Chuan Koay ${ }^{1,2}$ ${ }^{1}$ Department of Pathology, National University of Singapore and ${ }^{2}$ Molecular Diagnosis Centre, Department of Laboratory Medicine, National University Hospital, Singapore E-mail: patmst@nus.edu.sg

\section{References}

1 Godard B, ten Kate L, Evers-Kiebooms G, Ayme S: Population genetic screening programmes: principles, techniques, practices, and policies. Eur J Hum Genet 2003; 11 (Suppl 2): S49-S87.
2 Feder JN, Penny DM, Irrinki A et al: The hemochromatosis gene product complexes with the transferring receptor and lowers its affinity for ligand binding. Proc Natl Acad Sci USA 1998; 95: $1472-$ 1477.

3 Feder JN, Gnirke A, Thomas W et al: A novel MHC class I-like gene is mutated in patients with hereditary haemochromatosis. Nat Genet 1996; 13: 399-408.

4 Merryweather-Clarke AT, Pointon JJ, Jouanolle AM et al: Geography of HFE C282Y and H63D mutations. Genet Test 2000; 4: 183198.

5 Stott MK, Fellowes AP, Upton JD et al: Simple multiplex PCR for the simultaneous detection of the C282Y and H63D hemochromatosis (HFE) gene mutations. Clin Chem 1999; 45: $426-428$.

6 Merz JF, Kriss AG, Leonard DG et al: Diagnostic testing fails the test. Nature 2002; 415: 577-579. 